\title{
Numerical Optimization of Grey C.I. Casting using Simulation
}

\author{
M. N. Jadhav, K. H. Inamdar \\ (Department of Mechanical Engineering, Walchand College of Engineering, Sangli 416415, India)
}

\begin{abstract}
Foundries represent an important sector of the manufacturing industry and these foundry industries in developing countries suffer from poor quality and productivity due to number of process parameters involved in the casting process. Even in a completely controlled process, defects in casting are observed and hence casting process is also known as process of uncertainty which challenges explanation about the cause of casting defects. In sand casting process number of defects occur due to the wrong methoding of gating system, improper location of feeder and material properties. Production of this material need to be simulated and visualized it for mould filling, solidification, cooling and internal defects. In this paper numerical simulation technique has been used to study defects in sand casting related to methoding. Numerical simulation is useful tool for Casting in getting high quality castings and reducing product cost and rejection. The numerical simulation trial have been taken on current existing system and results showed that shrinkages, blow holes on casting. After modification of gating system, the simulation results showed that new gating system gives maximum yield as well as free from defect.
\end{abstract}

Keyword - Simulation, Casting defect, Methodology, Yield improvement.

\section{INTRODUCTION}

The metal casting is the basic manufacturing processes. It has been a primary manufacturing process for several centuries during $\mathrm{BC}$ and is so even today in the 21 st century. The principle of manufacturing a casting involves creating a hollow shape of the component to be prepared from the liquefied metal that is poured prepared mould cavity as per design and allowed it to solidification [1]. Today's global market is competitive and Automobiles OEMs (Original Equipment Manufacturers) have to launch the new product rapidly with better quality and to maintain their position with other OEMs. To fulfill this demand the automobile manufacturing OEMs should improve their processes, manage their suppliers and vendors. The one main supplier for OEMs is foundry industries. In automobile, the numbers of parts are manufactured from foundry and OEMs buyer demands defect free casting and strict to deliver on time. AutoCAST-X1 software for casting simulation is helpful to observe the mould fill, solidification, cooling and to predict the chances of location of internal defects such as shrinkage porosity, blow holes and cold shuts. It can be used for troubleshooting current castings and to develop modified new castings without shop floor trials [2,3]. Reis et al. [4] concluded that, the process modeling of shape casting is geometrically complex as well as computationally very challenging. Previously the methoding and defect prediction are modeled through empirical relations applied to the results obtained by simulation, which was not much reliable. Su-Ling lu et al. [5] have observed the casting defects inside the surface of a wet-type cylinder liner such as macro segregation and shrinkage porosities and coarse-grained zone. Performing the simulation pro-cast analyze filling stage, casting temperature, mould temperature, simulation and Comparison of the simulated results and those of defects observation indicates that casting defects occur nearly at the same location. Shang et al. [6] concluded that, micro-porosity in Al-Si castings is the most detrimental defects leads to high scrap loss in the production of commercial castings and severely prevents their widespread uses in many critical load bearing conditions. The effectiveness of the prediction of single solidification parameter and existing criteria functions was evaluated by correlating thermal data of simulation which was studied to experimentally obtained micro-porosity values. Svensson and T. Sjogren [7] concluded that, models for microstructure and mechanical property prediction have been implemented into casting simulation software. The present simulated casting is a ductile iron material and the critical parts of the simulation are cooling rate, nucleation of graphite and the restriction of ferrite by the chemical composition. Vasudev et al. [8] have done the casting simulation which has experimental validation has been adopted to generate the values of the gaps for a ductile iron cube casting of green sand mold. The minimum value of cavity wall gap was $35 \mathrm{~mm}$ and cavitycavity gap was $40 \mathrm{~mm}$. The cavity-cavity gap for hollow castings is observed to be approximately 0.75 times the casting wall thickness. A systematic procedure has been followed to determine the best combination of standard size of mold and the number of cavities for maximizing the mold yield. 


\section{METHODOLOGY}

Gating system is the cavity passage from where molten metal is poured from a ladle into the mould cavity. A gating system consists of pouring basin, sprue, sprue well, runners and the ingates. The function of the gating system is to obtain smooth, uniform and complete filling, which will create the minimum turbulence of metal and air aspiration, and will reduce sand erosion of mould wall and slag inclusions. Poorly designed gating system leads to undesired casting defects. The gating design should provide appropriate rate of molten metal flow to the correct locations to completely fill the mould cavity. In Fig. 1, B. Ravi has suggested simulation and optimization methodology which include five step procedures as.

1. Data Gathering:

Part Model, Material, Process Parameters, Method Design, Existing Defects

2. Method Design:

Parting Line, Cores, Feeders, Feedaids, Gating System, Mould Cavity Layout

3. Simulation:

Model Import, Mesh Generation, Material and Process Consumption, Visualisation

4. Optimization:

Modify Design, Simulation, Quality Check, Yield Check, Cost Check

\section{Project Closure:}

Method Report, Analysis Report, Image Slides, Compare Results, Archieve Projects.

Fig. 1: Casting simulation optimization methodology.

\subsection{Collection of Data}

The 3D model casting is shown in Fig. 2.

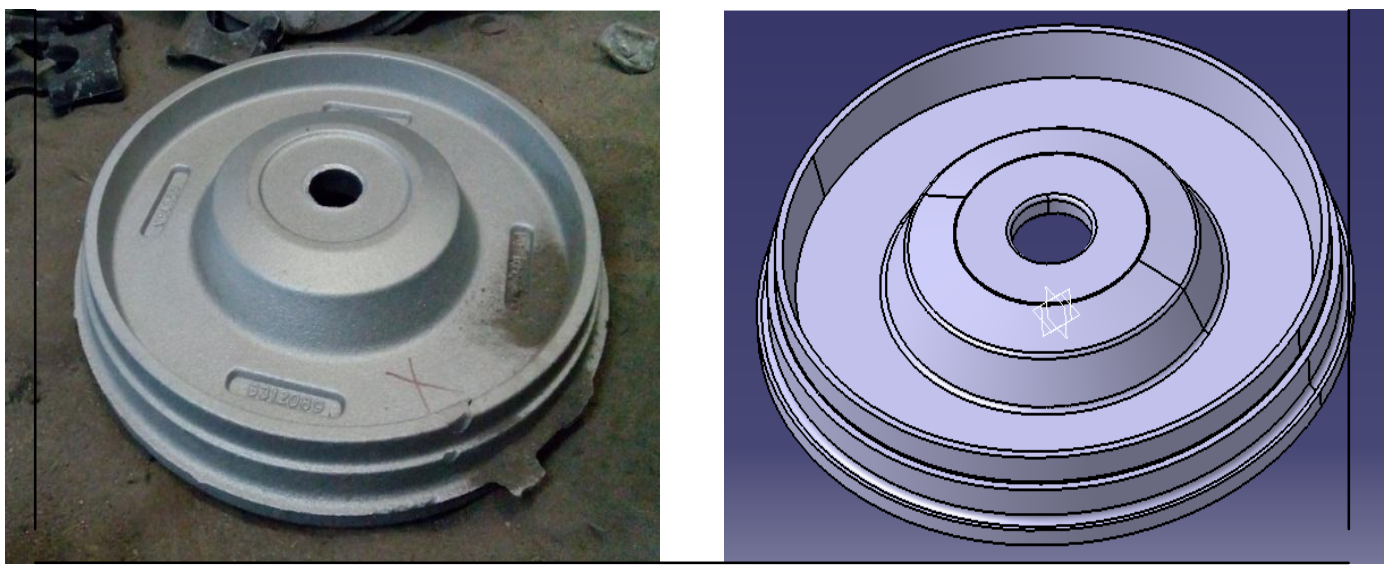

Fig. 2: 3D model of casting. 
The data collected for the Flywheel casting is shown in Table 1.

TABLE 1: Existing process details

\begin{tabular}{|c|c|c|}
\hline No. & Title & Details \\
\hline 1 & Mould material & Green sand \\
\hline 2 & Height of casting & $70 \mathrm{~mm}$ \\
\hline 3 & Tapping temperature $(\mathrm{Tp})$ & $1460-1470{ }^{\circ} \mathrm{C}$ \\
\hline 4 & Pouring Temperature & $1360-1420{ }^{0} \mathrm{C}$ \\
\hline 5 & Pouring time & $15-20 \mathrm{sec}$ \\
\hline 6 & Density of material & $7200 \mathrm{~kg} / \mathrm{m}^{3}$ \\
\hline 7 & Total weight of casting in mould box & $43.55 \mathrm{~kg}$ \\
\hline 8 & Number of cavities in mould box & 1 No. \\
\hline 9 & Size of box & $\begin{array}{l}700 \mathrm{~mm} \times 600 \mathrm{~mm} \text {, Cope } 230 \mathrm{~mm} \text {, } \\
\text { Drag } 170 \mathrm{~mm}\end{array}$ \\
\hline 10 & Total dimensions of mould box & $700 \mathrm{~mm}$ X 600mm X 400mm \\
\hline 11 & Shape of mould box & Rectangle \\
\hline 12 & Type gating system & Parting line gating system \\
\hline 13 & $\begin{array}{l}\text { Existing Yield of casting }= \\
\text { Total weight of good casting } \\
\text { Total weight of metal poured }\end{array}$ & $\begin{array}{l}\text { Yield }=\frac{43.55 * 100}{56.87} \\
\quad=76.58 \%\end{array}$ \\
\hline
\end{tabular}

\subsection{AutoCAST Simulation Studies}

The input for the Auto-Cast is geometric model created in CATIA V5R17 software. This model is imported in the AutoCAST-X1 as stl format. The gating design is based on the laws of fluid mechanics and empirical rules of gating for ferrous metal. It has been shown that an optimum gating system design could reduce the turbulence in metal flow and dross. A proper and convenient gating system is required in the production of quality casting with soundness of surface and without defects.

\subsection{Simulation of Existing Gating System}

In the current casting process, pressurized gating system is used. In this gating system sprue is connected to the runners and runner is connected to feeder through gate and metal enters into the cavity through neck. Maximum hot spot location at different section and Hot spot absorbed by sand riser are shown in Fig 3.

The simulation results shown in Fig. 4, that the hot spot are absorbed by feeder (sand riser). On other hand micro porosity has been found at some section shown in figure and a chances blow holes at the casting.

\subsection{Simulation of Modified Gating System}

In modified gating system the feeder have been removed and instead of that chill is used to increase the yield of the casting. The function of the chill is to help for directional solidification. Fig. 5 shows the chill used inside the core. And two ingates are replaced with four ingates.

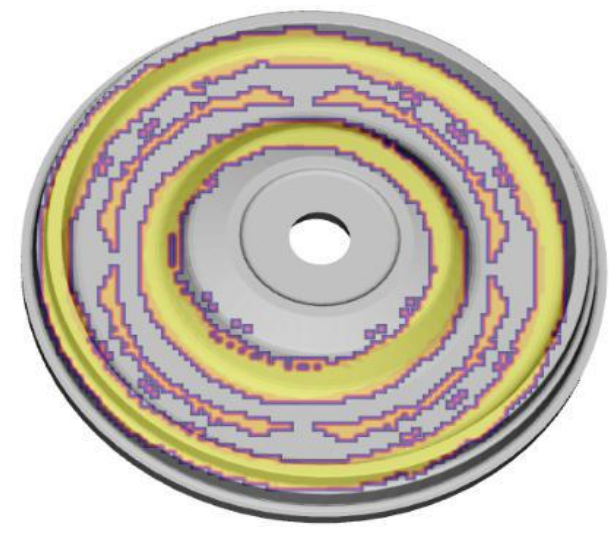

(a)

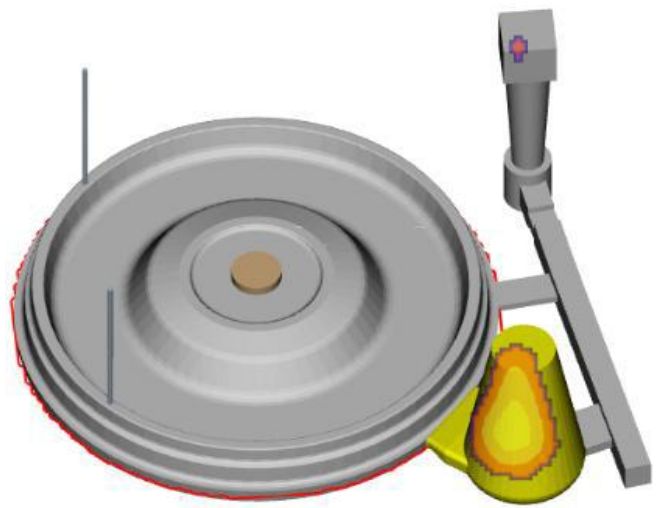

(b)

Fig. 3: (a) Maximum hot spot location at different section. (b) Hot spot absorbed by sand riser. 


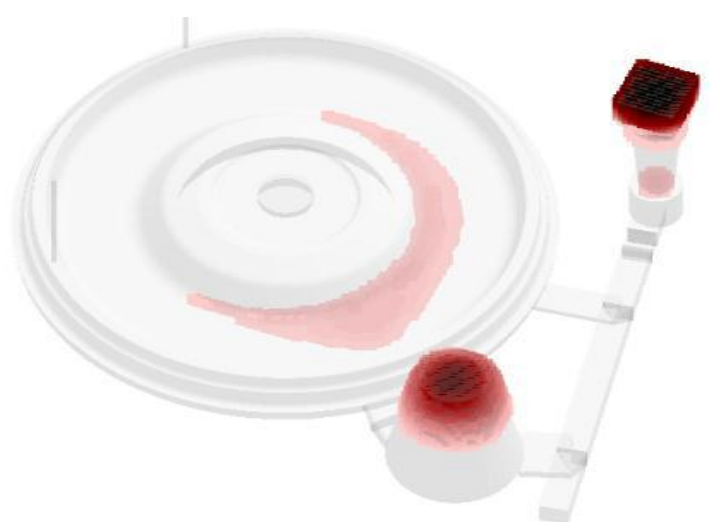

(a)

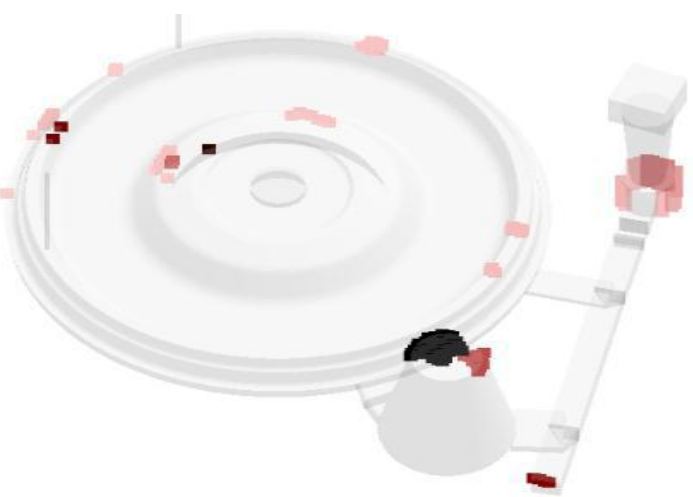

(b)

Fig. 4: (a) Chances of micro-porosity in casting, (b) Chances of blowhole.

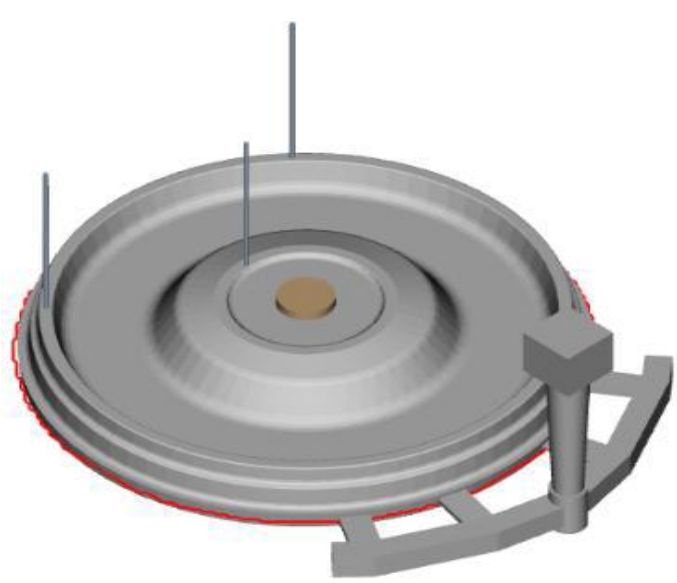

(a)

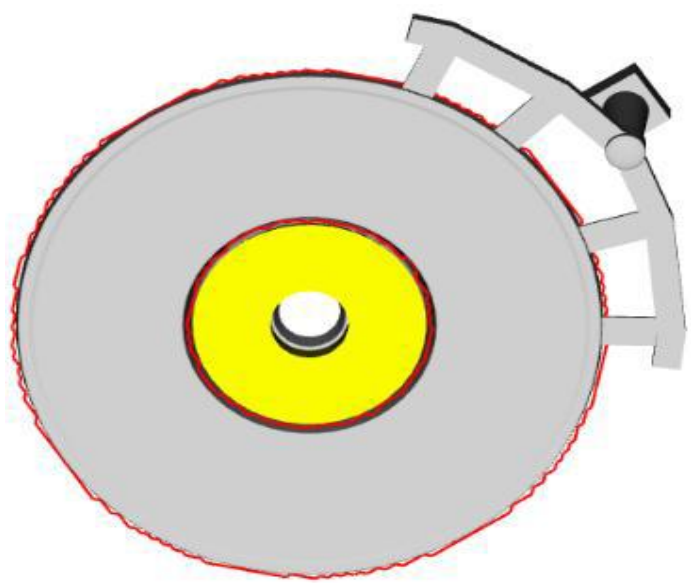

(b)

Fig. 5: (a) Casting with chill used inside the core and connected with gating system. (b) Chill used inside the core.

The use of chill inside the core has reduced the shrinkage defects and addition of vent at centre has also minimized the blowhole defects which are shown in Fig. 5. The use of chill helps in improvement for directional solidification.

Modified yield of casting $=\frac{43.55}{52.04}=83.71 \%$

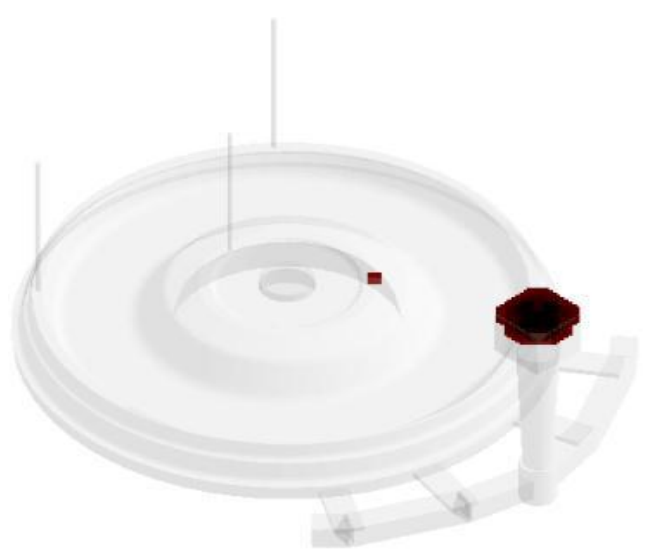

(a)

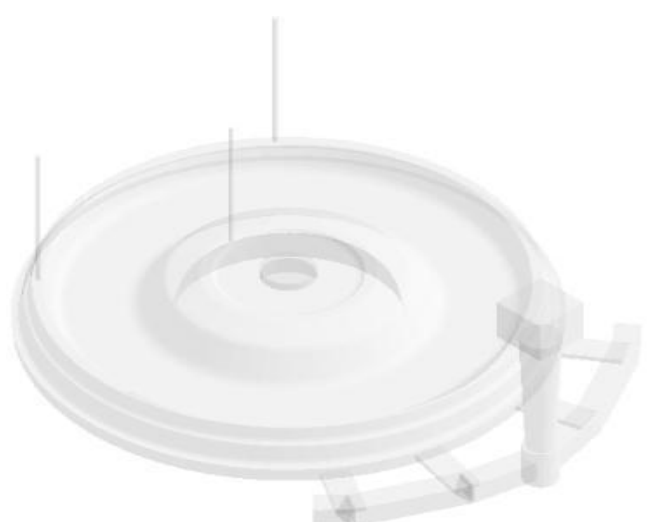

(b)

Fig. 6: (a) Chances of shrinkage-porosity in casting (b) Chances of blowhole. 


\subsection{Defect elimination}

After the first trial carried out for Existing gating system, the Shrinkage have been observed on sprue top of the gating as shown in the Fig.6. By providing the vent at the top of central dome shape, defect has been eliminated and defect free design was suggested for the casting of good quality.

\section{CONCLUSIONS}

The data survey and literature review makes it clear that the sand casting process is the completely controlled manufacturing process, where defects are unavoidable but it can be reduced by optimization of the casting gating system through simulation process.

a) Computer trials were successfully carried out to reduce the defects of the component.

b) After performing the trials with the help of computer simulation, a lot of metal, time, labor and cost were saved.

c) After modification in the gating system, the defects were removed and also yield improvement is $7.13 \%$ with the sound casting of MMPL.

\section{ACKNOWLEDGMENT}

The authors would like to thank the company Mantri Metallics Private Limited, Kagal M.I.D.C., Kolhapur for their involvement and support in this study.

\section{REFERENCES}

[1] Vivek S. Gondkar and K .H. Inamdar, Optimization of Casting Process Parameters through Simulation, IJAIEM, 13, 2014, 276- 283.

[2] Dr. B. Ravi , Casting simulation and optimization: benefits, bottlenecks, Indian foundry journal, 2008, 3-5.

[3] A. R. Narwade, C. M. Choudhari and B. E. Narkhede, Feeder Design And Analysis By Casting Simulation Software, International Journal of Informative \& Futuristic Research, 1, 2014, 281-291.

[4] A. Reis, Z. Xu, R.V. Tol and R. Neto, Modelling feeding flow related shrinkage defects in aluminum castings, Journal of Manufacturing Process, 14, 2012, 1-7.

[5] Su-Ling Lu, Fu-Ren Xiao, Shuang-Jie Zhang, Yong-Wei Mao and Bo Liao, Simulation study on the centrifugal casting wet-type cylinder liner based on ProCAST, Applied Thermal Engineering, 73, 2014, 510-519.

[6] L. H. Shang, F. Paray, J. E. Gruzleski, S. Bergeron, C. Mercadante and C. A. Loong, Prediction of micro-porosity in $\mathrm{Al}-\mathrm{Si}$ castings in low pressure permanent mould casting using criteria functions, International Journal of Cast Metals Research, 17, 2004, 193-200, 2004.

[7] I. Svensson and T. Sjogren, Modeling and Simulation of Mechanical Properties of Cast Irons With Different Morphologies of Graphite, International Journal of Metals Cast, 2009, 67-77.

[8] Vasudev D. Shinde, Durgesh Joshi, B. Ravi, and K. Narasimhan, Optimization of Mold Yield in Multi Cavity Sand Castings, Journal of Materials Engineering and Performance, 21, 2012. 